\title{
Efeito do paraquat e glyphosate sobre espécimes de poaceae e convolvulaceae em condições de déficit hídrico
}

\author{
Effect of paraquat and glyphosate for the control of poaceae and \\ convolvulaceae specimens on hydric deficit
}

\section{Lívia Felicio Barreto ${ }^{1}$, Ricardo Augusto Decaroㅇ, Marina Gomes da Silva², Fabiano Griesang ${ }^{1 *}$, Marcelo da Costa Ferreira ${ }^{1}$}

Resumo - O uso de herbicidas é uma prática muito utilizada para o controle de plantas daninhas. Entretanto, sua eficácia pode ser comprometida pela menor disponibilidade de água no ambiente, influenciando na absorção, translocação e metabolismo destes pelas plantas. $\mathrm{O}$ presente trabalho objetivou estudar o efeito dos herbicidas paraquat (Gramoxone ${ }^{\circledR}$ ) e glyphosate (Roundup Original ${ }^{\circledR}$ ) para o controle de capim-braquiária [Urochloa decumbens (Stapf) R.D.Webster (Poaceae)] e corda-de-viola [Merremia cissoides (Lam.) Hallier f. (Convolvulaceae)], em condições de déficit hídrico. $\mathrm{O}$ experimento foi conduzido em casa de vegetação, em delineamento experimental inteiramente casualizado e esquema fatorial $5 \times 3$, com três repetições. Foram consideradas cinco épocas de indução de déficit hídrico $(0,1,3,5$ e 7 dias) e três caldas de pulverização [paraquat, glyphosate e testemunha (com a aplicação de água, apenas)]. As avaliações de porcentagem de controle foram realizadas aos 2, 5, 7, 10, 14 e 21 dias após a aplicação dos tratamentos. Aos 21 dias foi determinado o teor de massa seca das plantas daninhas. Pelos resultados obtidos, observou-se que a partir de 5 dias com déficit hídrico, a eficácia dos herbicidas paraquat e glyphosate para o controle de capim-braquiária e corda-de-viola foi reduzida.

Palavras-chave: Urochloa decumbens, Merremia cissoides, controle químico, cana-de-açúcar

Abstract - The use of herbicides is very used by growers for the control of weeds. However, their effectiveness can be compromised by the reduction of water in the atmosphere, influencing its uptake, translocation and metabolism in plants. The objective of this study was to evaluate the efficacy of herbicides paraquat (Gramoxone ${ }^{\circledR}$ ) and glyphosate (Roundup Original ${ }^{\circledR}$ ) for the control of Urochloa decumbens (Stapf) R. D. Webster (Poaceae) and Merremia cissoides (Lam.) Hallier f. (Convolvulaceae) when submitted to hydric deficit. The experiment was conducted in greenhouse conditions with completely randomized design in factorial $5 \times 3$, considering three replicates. It was considered five induction conditions of hydric deficit $(0,1,3,5$ and 7 days) and three treatments (paraquat, glyphosate and untreated check, only water). The evaluations were performed at 2, 5, 7, 10, 14 and 21 days after treatment application. At 21 days, it was also determined the dry weight of weeds. From the results obtained, it was observed that from 5 days without irrigation the herbicides reduced their effectiveness for the control of weeds.

Keywords: Urochloa decumbens, Merremia cissoides, chemical control, sugarcane

Recebido: Junho 27, 2017. Aceito: Setembro 27, 2017.

${ }^{1}$ Universidade Estadual Paulista "Júlio de Mesquita Filho" - UNESP, Via de Acesso Prof. Paulo Donato Castellane, sn, CEP 14884-900, Jaboticabal, SP, Brasil. E-mail: fgriesang@hotmail.com

2 DuPont, Centro de Inovações Brasil, Paulínia, SP, Brasil. 


\section{Introdução}

As plantas daninhas são um dos principais componentes que impactam o desenvolvimento e a produtividade da cultura da cana-de-açúcar. Competem por recursos do meio essenciais para o crescimento das plantas como água, luz e nutrientes. Liberam substâncias alelopáticas, atuam como hospedeiros de pragas e doenças comuns à cana-de-açúcar, reduzem a qualidade da matéria-prima e interferem nas atividades de colheita e transporte (Christin et al., 2011).

A Urochloa decumbens (Stapf) R. D. Webster (Poaceae) (capim-braquiária) é uma espécie de planta daninha que possui metabolismo $\mathrm{C}_{4}$. Se for mal manejada, a espécie pode se alastrar rapidamente, de modo a infestar grandes áreas e causar prejuízos à produção das culturas (Lima et al., 2015). A evolução da via fotossintética $\mathrm{C}_{4}$ ocorreu provavelmente a partir da via $\mathrm{C}_{3}$, devido à pressão seletiva para ambientes secos, salinos e com temperaturas altas, com base no metabolismo de carbono e eficiência no uso de água (Christin et al., 2011). As plantas $\mathrm{C}_{4}$ perdem em torno de 100 moléculas de $\mathrm{H}_{2} \mathrm{O}$ por molécula de $\mathrm{CO}_{2}$ fixada enquanto que as plantas $\mathrm{C}_{3}$ perdem em torno de 600 moléculas de $\mathrm{H}_{2} \mathrm{O}$ por molécula de $\mathrm{CO}_{2}$ fixada (Dietrich et al., 2001). Assim, a maior adaptação à climas áridos, conferida às plantas de mecanismo fotossintético $\mathrm{C} 4$, pode ser explicada à sua maior condutância mesofílica, que por sua vez, resultam em menor condutância estomática e maior eficiência no uso da água (Varanasi et al., 2016).

Além do capim-braquiária, outro conjunto de espécies de plantas daninhas tem se destacado nas comunidades infestantes da cultura da cana-de-açúcar, pertencentes aos gêneros Ipomoea e Merremia, popularmente conhecidas como cordas-de-viola. Dentro do gênero Merremia, destacam-se a Merremia cissoides (Lam.) Hallier f. (Convolvulaceae) e a Merremia aegyptia (L.) Urb (Convolvulaceae).
As cordas-de-viola são problemas na cultura da cana-de-açúcar devido à competição por água, luz e nutrientes, entretanto, os prejuízos estão mais relacionados às operações de manejo da cana-de-açúcar, em especial na operação de colheita (Azania et al., 2009), intensificada à medida em que houve o incremento da mecanização na cultura (Almeida et al., 2017).

As elevadas perdas de produtividade ligadas à interferência de plantas daninhas fazem do uso de herbicidas uma prática essencial e generalizada (Scott e Van Deynze, 2017). Existem herbicidas registrados para a cana-de-açúcar com diferentes espectros de ação sobre plantas daninhas. Um deles é o glyphosate, pertencente ao grupo químico glicina substituída (inibidores da enzima EPSPs) e contém o N- (fosfonometil) glicina como ingrediente ativo. Outro importante ingrediente ativo é o paraquat ( $1,1^{\prime}$-dimetil-4,4'-bipiridilo), um herbicida de contato não seletivo, pertencente ao grupo dos bipiridílios, cuja comercialização pode estar com os dias contados no Brasil: Em meados do presente ano de 2017, a ANVISA se posicionou pelo banimento do herbicida, que poderá não mais ser comercializado após os três anos de prazo deliberado para transição (ANVISA, 2017).

Com a expansão do setor sucroalcooleiro, os produtores têm dificuldade em concentrar as aplicações de herbicidas somente na estação chuvosa, sendo necessária também a realização da pulverização na estação seca.

Em situações de limitação de disponibilidade de água, as plantas podem sofrer alterações em seus processos fisiológicos ligados diretamente à fotossíntese. As plantas reduzem a área foliar e reduzem a difusão do $\mathrm{CO}_{2}$ para dentro da folha devido ao fechamento dos estômatos. Diminuem a habilidade dos cloroplastos para fixar o $\mathrm{CO}_{2}$ que neles penetram. As folhas se enrolam e apresentam senescência (Faver et al., 1996). Podem ainda apresentarem engrossamento da cutícula das folhas e, assim, interferir na absorção de herbicidas (Pereira et al., 2010). A eficácia 
de um herbicida pode ser comprometida pela menor disponibilidade de água no ambiente no qual a planta daninha está se desenvolvendo, influenciando na sua absorção, translocação e metabolismo (Mani, 2017).

Por isso, tem-se a necessidade de desenvolver trabalhos que possam servir de base para as recomendações agrícolas e, desta forma, amenizar o impacto de condições de deficiência hídrica que estão cada vez mais frequentes nos dias atuais. Dessa maneira, o presente trabalho objetivou verificar os efeitos dos herbicidas paraquat e glyphosate sobre plantas de $U$. decumbens e $M$. cissoides submetidas a diferentes períodos de déficit hídrico.

\section{Material e métodos}

O experimento foi conduzido durante o período de setembro a outubro de 2015 em condições de casa de vegetação junto ao Departamento de Fitossanidade da FCAV/UNESP, localizado no município de Jaboticabal-SP, em latitude $21^{\circ} 14^{\prime} 05^{\prime}$ 'S, longitude $48^{\circ} 17^{\prime} 09^{\prime \prime} \mathrm{W}$ e altitude de 615 metros.

Vasos plásticos de 3,5 L foram preenchidos com uma mistura composta por diferentes granulometrias de solo na proporção 3:1:1 (solo argiloso: solo arenoso: esterco). Cada vaso foi utilizado como uma unidade experimental, em cada qual foram semeadas 20 sementes de plantas daninhas (cada espécie em seu respectivo vaso). Assim que as plantas atingiram dois pares de folhas verdadeiras, deixaram-se apenas 3 plantas por vaso. Os vasos foram mantidos com irrigações diárias até as épocas pré-determinadas para o início da submissão ao défícit hídrico.

Para cada espécie (braquiária ou corda-de-viola), o delineamento experimental foi inteiramente casualizado, com três repetições, em esquema fatorial $5 \times 3$, sendo cinco épocas de déficit hídrico $(0,1,3,5$ e 7 dias $)$ e três caldas de pulverização (constituídas de herbicida sistêmico, herbicida de contato e testemunha constituída de água, apenas), totalizando 45 vasos.
A interrupção da irrigação foi realizada de acordo com as épocas de déficit hídrico preconizadas $(0,1,3,5$ e 7 dias). No dia considerado 0 dias, foi realizada a aplicação dos tratamentos em todas as repetições. A corda de viola apresentava 5 a 6 folhas verdadeiras e a braquiária entre 2 e 3 perfilhos.

Dois herbicidas foram utilizados: paraquat (Gramoxone $200 \mathrm{SL}^{\circledR}$, Syngenta) na dosagem de 1,5 L de produto comercial por hectare e glyphosate (Roundup original $840 \mathrm{CS}^{\circledR}$, Monsanto) na dosagem de 3,0 L de produto comercial por hectare (Tabela 1). O volume de calda considerado foi de $200 \mathrm{~L} \mathrm{ha}^{-1}$. As aplicações dos herbicidas foram realizadas com um pulverizador costal pressurizado a $\mathrm{CO}_{2}$ com pressão constante de 6,08 bar. A barra de aplicação foi equipada com duas pontas de pulverização do modelo XR 11002 , espaçadas a 0,5 metro entre si e altura de $0,5 \mathrm{~m}$ em relação ao topo das plantas. A data e o horário da aplicação, bem como as condições dos principais elementos climáticos durante a pulverização encontram-se na Tabela 2 .

Após $24 \mathrm{~h}$ da aplicação dos tratamentos, tempo suficiente para a penetração dos herbicidas nas

Tabela 1. Descrição dos tratamentos experimentais utilizados no ensaio para controle das plantas daninhas na cultura da cana-de-açúcar. Jaboticabal, SP, 2015.

\begin{tabular}{|c|c|c|c|}
\hline Tratamentos & Produtos & $\begin{array}{c}\text { Época } \\
\text { estresse } \\
\text { hídrico }\end{array}$ & $\begin{array}{c}\text { Doses } \\
\left(\mathbf{L} \text { p.c. } \text { ha }^{-1}\right)\end{array}$ \\
\hline 1 & Testemunha & 0 & 0 \\
\hline 2 & Testemunha & 1 & 0 \\
\hline 3 & Testemunha & 3 & 0 \\
\hline 4 & Testemunha & 5 & 0 \\
\hline 5 & Testemunha & 7 & 0 \\
\hline 6 & Paraquat & 0 & 1,5 \\
\hline 7 & Paraquat & 1 & 1,5 \\
\hline 8 & Paraquat & 3 & 1,5 \\
\hline 9 & Paraquat & 5 & 1,5 \\
\hline 10 & Paraquat & 7 & 1,5 \\
\hline 11 & Glyphosate & 0 & 3,0 \\
\hline 12 & Glyphosate & 1 & 3,0 \\
\hline 13 & Glyphosate & 3 & 3,0 \\
\hline 14 & Glyphosate & 5 & 3,0 \\
\hline 15 & Glyphosate & 7 & 3,0 \\
\hline
\end{tabular}


plantas, foi feita a irrigação de $5 \mathrm{~mm}$ nos vasos. Este valor foi mantido durante as irrigações diárias do experimento.

As avaliações de eficiência do controle sobre as plantas daninhas para os tratamentos ocorreram aos 2, 5, 7, 10, 14 e 21 dias após a aplicação (DAA) utilizando-se a metodologia proposta por ALAM (1974). Foram dadas notas de porcentagem de controle baseando-se nos sintomas apresentados em relação às plantas do tratamento testemunha. As notas variaram de 0 (ausência de controle) a 100\% (controle absoluto). Além da porcentagem de controle, determinou-se a massa seca das plantas daninhas, por meio da separação da raiz e parte aérea aos 21 dias após a aplicação dos tratamentos. A secagem foi feita em estufa a $60{ }^{\circ} \mathrm{C}$ por $72 \mathrm{~h}$.

Os dados obtidos de porcentagem de controle e matéria seca foram submetidos à análise de variância pelo teste F. A comparação entre as médias foi realizada através do teste de Tukey, a $5 \%$ de probabilidade.

\section{Resultados e discussão}

Os herbicidas glyphosate e paraquat foram eficientes no controle de corda-de-viola e capim-braquiária. Entretanto, esta eficiência variou de acordo com o período de déficit hídrico e com o período após a aplicação dos herbicidas (épocas de avaliação).

Aos 2 e 5 dias após a aplicação (DAA), o glyphosate não promoveu um bom controle das duas espécies, fato explicado pela ação sistêmica do herbicida. Contudo, para capim-braquiária, o produto apresentou um excelente controle onde não houve indução do déficit hídrico. À medida em que essa condição de déficit hídrico foi aumentada, foi observada redução na eficiência dos herbicidas (Figura 1). Em um estudo desenvolvido por Rocha-Pereira et al. (2012) também se observou controle insatisfatório para plantas de $U$. decumbens submetidas a períodos de estresse hídrico. Sendo assim, os períodos de déficit hídrico de 5 e 7 dias influenciaram negativamente no controle comprovando que a eficiência de herbicidas é prejudicada pelo baixo teor de água no solo e a possível indução de estresse nas plantas (Azania et al., 2009; Correia e Kronka Junior, 2010).

Até 3 dias de déficit hídrico, o herbicida glyphosate demonstrou maior percentual de controle de capim-braquiária do que de corda-de-viola. Isso talvez seja explicado pelo produto ser sistêmico e pelo metabolismo destas plantas daninhas serem diferentes (Varanasi et al., 2016). Capim-braquiária é uma planta $\mathrm{C}_{4}$. Por isso, podem ter menor condutância estomática, economizando água e melhorando a ação do herbicida.

O herbicida paraquat controlou de maneira mais rápida as duas espécies de plantas daninhas (Tabela 1). Nos primeiros dias após a aplicação deste herbicida, foram observados sintomas de clorose intensa e necrose dos tecidos (Figura 1), sintomas corriqueiramente observados para este herbicida (Montgomery et al., 2017). Não foram observadas diferenças expressivas no controle de corda-de-viola para os diferentes períodos de déficit hídrico. A dose do paraquat utilizada neste experimento pode explicar o comportamento semelhante no controle de corda-de-viola ao longo dos diferentes dias de avaliações. Doses mais elevadas deste herbicida podem promover controle

Tabela 2. Data, horário e condições dos principais elementos climáticos nas aplicações do herbicida. Jaboticabal, SP, 2015.

\begin{tabular}{|c|c|c|c|c|c|c|}
\hline \multirow{2}{*}{ Data } & \multicolumn{2}{|c|}{ Horário } & \multirow{2}{*}{$\begin{array}{c}\text { Temp. }\left({ }^{\circ} \mathrm{C}\right) \\
\text { Ar }\end{array}$} & \multirow{2}{*}{ U.R. (\%) } & \multirow{2}{*}{ Vento $(\mathrm{m} / \mathrm{s})$} & \multirow{2}{*}{$\begin{array}{l}\text { Presença de } \\
\text { nuvens (\%) }\end{array}$} \\
\hline & Início & Fim & & & & \\
\hline $13 / 10 / 2015$ & $10: 00$ & $10: 20$ & 28.6 & 51.0 & 1.0 & 50 \\
\hline
\end{tabular}


de plantas daninhas no estádio de até 6 folhas independente do manejo hídrico (Pereira et al., 2010).

No caso do capim-braquiária, notou-se um menor controle aos 21 DAA no tratamento constituído de 7 dias de déficit hídrico (Tabela 3). Além disso, ambas espécies rebrotaram após alguns dias da aplicação.

\section{Urochloa decumbens}

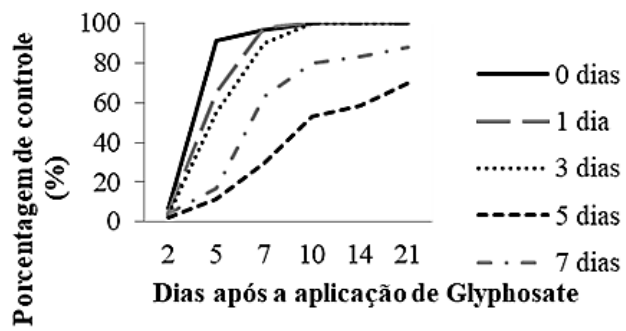

Merremia cissoides

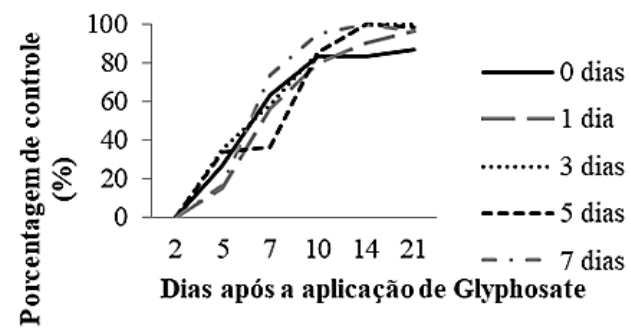

Os dados obtidos referentes à matéria seca corroboram com o que foi apresentado nos parágrafos anteriores. De maneira geral, o aumento do déficit hídrico diminuiu a eficiência dos herbicidas (Tabelas 4 e 5). Plantas estressadas por déficit hídrico, devido ao baixo teor de água no solo, afetam negativamente a atividade dos herbicidas (Zanatta et al., 2008).

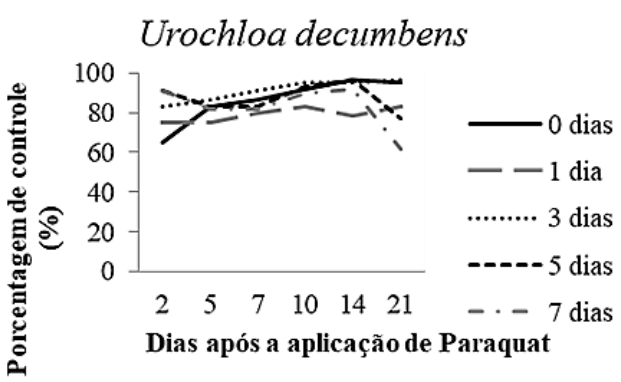

Merremia cissoides

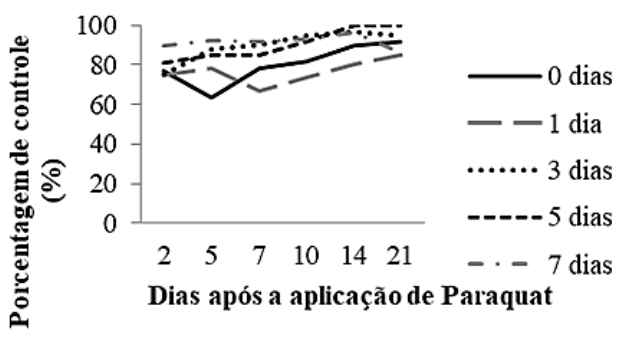

Figura 1. Notas de controle (\%) de Urochloa decumbens e Merremia cissoides em função dos diferentes tratamentos, de acordo com a escala ALAM (1974). (A) Aplicação de Glyphosate; (B) Aplicação de Paraquat. Jaboticabal, SP, 2015.

Tabela 3. Porcentagem de controle de capim-braquiária (U. decumbens) e corda-de-viola (M. cissoides) aos 21 dias após a aplicação dos tratamentos. Jaboticabal, SP, 2015.

\begin{tabular}{cccccccc}
\hline \multirow{2}{*}{$\begin{array}{c}\text { Dias de estresse } \\
\text { hídrico }\end{array}$} & \multicolumn{3}{c}{ U. decumbens } & & \multicolumn{3}{c}{ M. cissoides } \\
\cline { 2 - 3 } & $\begin{array}{c}\text { Sem } \\
\text { herbicida }\end{array}$ & Glyphosate & Paraquat & & $\begin{array}{c}\text { Sem } \\
\text { herbicida }\end{array}$ & Glyphosate & Paraquat \\
\hline 0 & $0,00 \mathrm{aB}$ & $100,00 \mathrm{aA}$ & $95,00 \mathrm{aA}$ & & $0,00 \mathrm{aB}$ & $86,67 \mathrm{aA}$ & $91,67 \mathrm{aA}$ \\
1 & $0,00 \mathrm{aB}$ & $100,00 \mathrm{aA}$ & $83,33 \mathrm{abA}$ & & $0,00 \mathrm{aB}$ & $96,67 \mathrm{aA}$ & $85,00 \mathrm{aA}$ \\
3 & $0,00 \mathrm{aB}$ & $100,00 \mathrm{aA}$ & $96,66 \mathrm{aA}$ & & $0,00 \mathrm{aB}$ & $100,00 \mathrm{aA}$ & $95,00 \mathrm{aA}$ \\
5 & $0,00 \mathrm{aB}$ & $70,00 \mathrm{bA}$ & $76,66 \mathrm{abA}$ & & $0,00 \mathrm{aB}$ & $98,67 \mathrm{aA}$ & $100,0 \mathrm{aA}$ \\
7 & $0,00 \mathrm{aC}$ & $88,33 \mathrm{abA}$ & $61,66 \mathrm{bB}$ & & $0,00 \mathrm{aB}$ & $96,67 \mathrm{aA}$ & $86,67 \mathrm{aA}$ \\
F para interação & & $2,49^{*}$ & & & & $0,73^{\mathrm{ns}}$ & \\
C.V. (\%) & & 18 & & & 14,28 & \\
\hline
\end{tabular}

Médias seguidas de mesma letra minúscula na coluna e maiúscula na linha para cada espécie de planta daninha não diferem estatisticamente entre si pelo teste de Tukey a 5\% de probabilidade; * significativo ao nível de $5 \%(\mathrm{p}<0,05)$ de probabilidade; ${ }^{\text {ns }}$ não significativo. 
Tabela 4. Médias de matéria seca (g) da parte aérea e raiz de capim-braquiária (Urochloa decumbens) aos 21 dias após a aplicação dos tratamentos. Jaboticabal, SP, 2015.

\begin{tabular}{|c|c|c|c|c|c|c|}
\hline \multirow{2}{*}{$\begin{array}{c}\text { Dias de estresse } \\
\text { hídrico }\end{array}$} & \multicolumn{3}{|c|}{ Matéria seca da Parte Aérea (g) } & \multicolumn{3}{|c|}{ Matéria seca da Raiz (g) } \\
\hline & $\begin{array}{c}\text { Sem } \\
\text { herbicida }\end{array}$ & Glyphosate & Paraquat & $\begin{array}{c}\text { Sem } \\
\text { herbicida }\end{array}$ & Glyphosate & Paraquat \\
\hline 0 & $11,16 \mathrm{aA}$ & $2,87 \mathrm{bB}$ & $4,74 \mathrm{aB}$ & $32,40 \mathrm{aA}$ & $1,88 \mathrm{aB}$ & $2,43 \mathrm{aB}$ \\
\hline 1 & $8,71 \mathrm{abA}$ & $3,99 \mathrm{abB}$ & $5,51 \mathrm{aB}$ & $35,15 \mathrm{aA}$ & $1,34 \mathrm{aB}$ & $3,30 \mathrm{aB}$ \\
\hline 3 & $8,81 \mathrm{abA}$ & $6,23 \mathrm{aB}$ & $6,17 \mathrm{aA}$ & $19,96 \mathrm{bA}$ & $0,99 \mathrm{aB}$ & $2,02 \mathrm{aB}$ \\
\hline 5 & $6,07 \mathrm{bA}$ & $4,30 \mathrm{abA}$ & $4,82 \mathrm{aA}$ & $12,69 \mathrm{bA}$ & $1,67 \mathrm{aB}$ & $2,64 \mathrm{aB}$ \\
\hline 7 & $6,89 \mathrm{bA}$ & $4,54 \mathrm{abA}$ & $6,17 \mathrm{aA}$ & $12,50 \mathrm{bA}$ & $0,67 \mathrm{aB}$ & $1,46 \mathrm{aB}$ \\
\hline F para interação & & $4,72 * *$ & & & $6,53 * *$ & \\
\hline C.V. $(\%)$ & & 21,16 & & & 46,61 & \\
\hline
\end{tabular}

Médias seguidas de mesma letra minúscula na coluna e maiúscula na linha para cada espécie de planta daninha não diferem estatisticamente entre si pelo teste de Tukey a $5 \%$ de probabilidade; $* *$ significativo ao nível de $1 \%(\mathrm{p}<0,01)$ de probabilidade.

Tabela 5. Médias de matéria seca ( $\mathrm{g}$ ) da parte aérea e raiz de corda-de-viola (Merremia cissoides) aos 21 dias após a aplicação dos tratamentos. Jaboticabal, SP, 2015.

\begin{tabular}{|c|c|c|c|c|c|c|}
\hline \multirow{2}{*}{$\begin{array}{l}\text { Dias de } \\
\text { estresse } \\
\text { hídrico }\end{array}$} & \multicolumn{3}{|c|}{ Matéria seca da Parte Aérea (g) } & \multicolumn{3}{|c|}{ Matéria seca da Raiz (g) } \\
\hline & Sem herbicida & Glyphosate & Paraquat & Sem herbicida & Glyphosate & Paraquat \\
\hline 0 & $5,28 \mathrm{aA}$ & $1,31 \mathrm{aB}$ & $2,40 \mathrm{aAB}$ & $5,03^{1}$ aA & $0,19 \mathrm{aB}$ & $2,12 \mathrm{aAB}$ \\
\hline 1 & $5,78 \mathrm{aA}$ & $2,12 \mathrm{aB}$ & $1,87 \mathrm{aB}$ & $4,67 \mathrm{aA}$ & $0,72 \mathrm{aA}$ & $1,74 \mathrm{aA}$ \\
\hline 3 & $6,50 \mathrm{aA}$ & $1,35 \mathrm{aB}$ & $0,71 \mathrm{aB}$ & $6,54 \mathrm{aA}$ & $0,31 \mathrm{aB}$ & $0,27 \mathrm{aB}$ \\
\hline 5 & 4,94 aA & $2,69 \mathrm{aA}$ & $2,44 \mathrm{aA}$ & $6,36 \mathrm{aA}$ & $1,63 \mathrm{aA}$ & $2,10 \mathrm{aA}$ \\
\hline 7 & $4,75 \mathrm{aA}$ & $3,32 \mathrm{aA}$ & $2,48 \mathrm{aA}$ & $8,47 \mathrm{aA}$ & $3,51 \mathrm{aAB}$ & $1,86 \mathrm{aB}$ \\
\hline $\begin{array}{l}\text { F para } \\
\text { interação }\end{array}$ & & $0,81^{\mathrm{ns}}$ & & & $0,46^{\text {ns } 2}$ & \\
\hline C.V. $(\%)$ & & 53,64 & & & 37,05 & \\
\hline
\end{tabular}

${ }^{1}$ Dados originais. Médias seguidas de mesma letra minúscula na coluna e maiúscula na linha para cada espécie de planta daninha não diferem estatisticamente entre si pelo teste de Tukey a $5 \%$ de probabilidade; ${ }^{\text {ns }}$ não significativo; ${ }^{2}$ Dados transformados em $\sqrt{x+0,5}$ para análises estatísticas.

Sendo assim, a observância de fatores ambientais é recomendado para que o herbicida (aplicado em pós-emergência) possa alcançar maior eficiência, uma vez que o maior efeito é alcançado no momento em que as plantas apresentam elevada atividade metabólica (Cieslik et al., 2013). Assim, o manejo químico é mais eficaz quando não ocorrem condições de déficit hídrico, pois a água disponível no solo e o intenso desenvolvimento das plantas daninhas favorecem a absorção dos herbicidas e, consequentemente, sua ação no controle destas.

\section{Conclusões}

Os herbicidas glyphosate e paraquat promovem o controle eficiente de plantas juvenis de U. decumbens e M. cissoides. Em condições de 5 dias ou mais de déficit hídrico prejudicam a eficácia desses produtos no controle dessas espécies de plantas daninhas.

\section{Referências}

ALAM - Asociación Latinoamericana de Malezas. Recomendaciones sobre unificación de los sistemas 
de evaluación en ensayos de control de malezas. ALAM, v. 1, n. 1, p. 35-38, 1974.

Almeida, D.P.; Ferreira, M.C.; Leite, G.J.; Velloso, C.P.; Griesang, F.; Santos, R.T.S. Volumes de calda, uso de adjuvante e intervalos sem chuva no controle de plantas-daninhas com sulfentrazone. Revista Brasileira de Herbicidas, v.16, p.163-172, 2017.

ANVISA - Agência Nacional de Vigilância Sanitária. Agrotóxicos: Anvisa finaliza reavaliação toxicológica do Paraquate. Brasília: ANVISA, 2017. Disponível em: $<$ http://portal.anvisa.gov. br>. Acesso em: 25 set. 2017.

Azania, C.A.M.; Azania, A.A.P.M.; Pizzo, I.V.; Schiavetto, A.R.; Zera, F.S.; Marcari, M.A.; Santos, J.L. Manejo químico de Convolvulaceae e Euphorbiaceae em cana-de-açúcar em período de estiagem. Planta Daninha, v.27, n.4, p.841848, 2009.

Christin, P.A.; Sage, T.L.; Edwards, E.J.; Ogburn, R.M.; Khoshravesh, R.; Sage, R.F. Complex evolutionary transitions and the significance of C3-C4 intermediate forms of photosynthesis in Molluginaceae. International Journal of Organic Evolution, v.65, n.3, p.643-660, 2011. Cieslik, L.F.; Vidal, R.A.; Trezzi, E. Environmental factors affecting the efficacy of ACCase-inhibiting herbicides: a Review. Planta Daninha, v.31, n.211, p.483-489, 2013.

Correia, N.M.; Kronka Junior, B. Eficácia de herbicidas aplicados nas épocas seca e úmida para o controle de Euphorbia heterophylla na cultura da cana-de-açúcar. Planta Daninha, v.28, n.4, p.853-863, 2010.

Dietrich, P.; Sanders, D.; Hedrich, R. The role of ion channels in light- dependent stomatal opening. Journal of Experimental Botany, n.52, p.1959-1967, 2001.
Faver, K.L.; Gerik, T.J.; Thaxton, P.M.; El-Zik, K.M. Late season water stress in cotton: Leaf gas exchange and assimilation capacity. Crop Science, v.36, p.922-928, 1996.

Lima, L.K.S.; Costa Araújo, R.; Santos, J.P.S.; Lopes, M.D.F.Q. Fitossociologia de plantas daninhas em pomar de goiabeiras em diferentes épocas de amostragem. Revista Biociências, v.21, n.1, p.45-55, 2015.

Mani, P. Impact of concurrent weed or herbicide stress with other biotic and abiotic stressors on crop production. In: Bagavathiannan, M.; Singh, V.; Govindasamy, P.; Abugho, S.B.; Liu, R. (Ed.). Plant tolerance to individual and concurrent stresses. 1.ed. New Delhi: Springer, 2017. p.33-45.

Montgomery, G.B.; Treadway, J.A.; Reeves, J.L.; Steckel, L.E. Effect of time of day of application of 2,4-D, Dicamba, Glufosinate, Paraquat, and Saflufenacil on horseweed (Conyza canadensis) control. Weed Technology, v.31, n.4, p.550-556, 24 ago. 2017.

Pereira, M.R.R.; Martins, D.; Silva, J.I.C.; Rodrigues-Costa, A.C.P.; Klar, A.E. Efeito de herbicidas sobre plantas de Brachiaria plantaginea submetidas a estresse hídrico. Planta Daninha, v.28, n.esp., p.1047-1058, 2010.

Rocha-Pereira, M.R.; Klar, A.E.; Martins, D.; Souza, G.S.F.; Villalba, J. Effect of water stress on herbicide efficiency applied to Urochloa decumbens. Ciencia e Investigación Agraria, v.39, n.1, 2012.

Scott, S.M.; Van Deynze, B. Hoes to herbicides: economics of evolving weed management in the United States. European Journal of Development Research, v.29, n.3, p.560-574, 2017.

Varanasi, A.; Vara Prasad, P.; Jugulam, M. Impact of climate change factors on weeds and herbicide efficacy. Advances in Agronomy, v.135, p.40, 2016. 
Zanatta, J.F.; Procópio, S.O.; Manica, R.; herbicida fomesafen no controle de Amaranthus Pauletto, E.A.; Cargnelutti Filho, A.; Vargas, hybridus. Planta Daninha, v. 26, n. 1, p. 143L.; et al. Teores de água no solo e eficácia do 155, 2008. 